\title{
Association between infant nutrition and anthropometry, and pre-pubertal body composition in urban South African children - ERRATUM
}

\author{
J. Kagura, A. B. B. Feeley, L. K. Micklesfield, J. M. Pettifor and S. A. Norris
}

doi:10.1017/S2040174412000475, published by Cambridge University Press, 5 July 2012.

In the author affiliations, the primary affiliation for L. K. Micklesfield was omitted, instead of:

L. K. Micklesfield ${ }^{2}$

${ }^{2} \mathrm{MRC} /$ Exercise Science and Sports Medicine, University of Cape Town, Johannesburg, South Africa

it should read:

L. K. Micklesfield ${ }^{1,2}$

${ }^{1}$ MRC/Wits Developmental Pathways of Health Research Unit, Department of Paediatrics, Faculty of Health Sciences, University of the Witwatersrand, Johannesburg, South Africa

${ }^{2}$ UCT/MRC Research Unit for Exercise Science and Sports Medicine, Department of Human Biology, University of Cape Town, Cape Town, South Africa

\section{Reference}

1. Kagura J, Feeley ABB, Micklesfield LK, Pettifor JM, Norris SA. Association between infant nutrition and anthropometry, and pre-pubertal body composition in urban South African children. $J$ Dev Orig Health Dis. 2012; 3(6), 415-423. Published online 5 July 2012; doi:10.1017/S2040174412000475. 